\title{
Treatment of rocuronium-induced anaphylaxis using sugammadex \\ - A case report -
}

Received September 11, 2020

Revised October 28, 2020

Accepted October 28, 2020

\section{Sun-Min Kim, Sei-hoon Oh, and Seung-Ah Ryu}

Department of Anesthesiology and Pain Medicine, Seoul Medical Center, Seoul, Korea

Background: Perioperative anaphylaxis is a life-threatening clinical condition characterized by severe respiratory and cardiovascular manifestations. Neuromuscular blocking agents are the most common cause of anaphylaxis during anesthesia.

Case: We report a case of rocuronium-induced anaphylaxis treated with sugammadex. A 75-year-old female was scheduled to undergo spinal surgery. She had no history of allergies. After the injection of rocuronium, she developed hypotension and tachycardia, and skin rashes and urticaria appeared. The patient received sugammadex to delay the operation, and her vital signs were stabilized. On the 76th postoperative day, we performed intradermal tests for rocuronium, propofol, and cefazolin. Diluted rocuronium alone induced $14 \mathrm{~mm}$ of flare and $8 \mathrm{~mm}$ of wheal within $5 \mathrm{~min}$, both of which disappeared within $15 \mathrm{~min}$ after the intradermal injection.

Conclusions: Sugammadex is a useful rocuronium antagonist that can be used to treat rocuronium-induced anaphylaxis.

Keywords: Anaphylaxis; Anesthesia; Rocuronium; Sugammadex; Shock; Treatment.

\section{Corresponding author}

Seung-Ah Ryu, M.D.

Department of Anesthesiology and Pain Medicine, Seoul Medical Center, 156 Sinnae-ro, Jungnang-gu, Seoul 02053, Korea

Tel: 82-2-2276-7659

Fax: 82-2-8876-7658

E-mail: modoom@hanmail.net
Anaphylaxis is defined as a serious, life-threatening, generalized or systemic hypersensitivity reaction with a rapid onset [1].

Although anaphylaxis during anesthesia induction occurs only in approximately 1 of 20,000 cases, it can be life-threatening. Neuromuscular blocking agents, particularly, rocuronium and succinylcholine, are the most common pharmacologic causes in approximately $60 \%$ to $70 \%$ of cases [2-4]. The first choice of treatment for anaphylaxis during anesthesia is immediate discontinuation of the anaphylactic agent and the use of drugs that improve the hemodynamic status of the patient [3]. Sugammadex is a selective antagonist of rocuronium and rapidly reverses rocuronium-induced neuromuscular blockade [5]. This pharmacological characteristic of sugammadex favors its use in the treatment of rocuronium-induced anaphylaxis [6]. We report a case of rocuronium-induced anaphylaxis treated with sugammadex.

\section{CASE REPORT}

A written informed consent form was obtained for publication of this report. A 75-year-old female (weight, $51 \mathrm{~kg}$; height, $146 \mathrm{~cm}$ ) was scheduled to undergo a decompressive lumbar laminectomy and interbody fusion (lumbar level, 3-4 and 4-5) under general anesthesia. She had well-controlled hypertension. Five years earlier, she underwent an uneventful procedure under general anesthesia

This is an Open Access article distributed under the terms of the Creative Commons Attribution Non-Commercial License (http://creativecommons.org/licenses/by-nc/4.0) which permits unrestricted non-commercial use, distribution, and reproduction in any medium, provided the original work is properly cited.

Copyright (C) the Korean Society of Anesthesiologists, 2021 
(transobturator vaginal tape operation). She reported no known allergy to medication, food, or latex. Results of preoperative laboratory examinations, chest radiography, electrocardiography, transthoracic echocardiography, thallium scan, and pulmonary function tests were normal.

On arrival in the operating room, she had a noninvasive blood pressure of 102/63 mmHg, a heart rate of 98 beats/ min, and an oxygen saturation $\left(\mathrm{SpO}_{2}\right)$ at room air of $100 \%$. After starting pre-oxygenation anesthesia induction, the patient received propofol (100 $\mathrm{mg}$ ) for anesthesia induction and rocuronium bromide $(50 \mathrm{mg})$ to facilitate tracheal intubation. Anesthesia was maintained with 4-8 vol\% desflurane and target-controlled infusion of remifentanil (2 $\mathrm{mg} ; 2 \mathrm{ng} / \mathrm{ml}$ ). Thereafter, endotracheal intubation was performed. A 16-gauge peripheral intravenous cannula and a 20-gauge arterial line were placed. The results of the first arterial blood gas analysis were within the normal range $\left(\mathrm{pH}, 7.43 ; \mathrm{pCO}_{2}, 37 ; \mathrm{pO}_{2}, 168\right)$. The patient was placed in the prone position after administration of prophylactic antibiotics (cefazoline, $2 \mathrm{~g}$ ).

Five minutes after the position change, which was performed $10 \mathrm{~min}$ after induction, an arterial blood pressure of $68 / 43 \mathrm{mmHg}$ and sinus tachycardia of 113 beats/min were noted. Even though the skin test for sensitivity to cefazoline was negative, the prophylactic antibiotics were discontinued immediately and ephedrine (10 mg), phenylephrine (200 mg), 1,100 ml of crystalloid, and $500 \mathrm{ml}$ of colloid were administered. The follow-up arterial blood analysis results remained unchanged. Despite these interventions, the blood pressure decreased further to 35/25 $\mathrm{mmHg}$ and the heart rate was 130 beats/min. Subsequently, dexamethasone (5 mg) and pheniramine (4 mg) were administered. However, the patient's skin symptoms continued to worsen and spread from her trunk to her head. We strongly suspected an anaphylactic reaction, and epinephrine infusion $(0.1 \mu \mathrm{g} / \mathrm{kg} / \mathrm{min})$ was started after administration of an intravenous epinephrine bolus. Despite appropriate traditional management, the skin symptoms worsened, and the situation was still critical. The epinephrine infusion dose was increased every minute and bolus drugs were needed to restore the blood pressure. A decision was made to delay the surgery and sugammadex (200 $\mathrm{mg} ; 4 \mathrm{mg} / \mathrm{kg}$ ) was administered to reverse the neuromuscular blockade because her train-of-four ratio was 0.2 [7]. Shortly thereafter, the patient's arterial blood pressure recovered to the pre-induction level. Hemodynamic data after sugammadex injection were as follows: heart rate, 102 beats/min; blood pressure, 95/48 mmHg; and oxygen saturation, $100 \%$. The patient was sedated with a bolus of midazolam and transferred to the intensive care unit for further observation. She was extubated within 30 min of arrival in the intensive care unit, and no further vasopressor support was required (Fig. 1).

The patient was discharged without any complications. One month later, she visited the Department of Allergy Medicine for the identification of the agent that caused her intraoperative anaphylaxis. Intradermal skin tests were performed four weeks later with rocuronium and cefazoline. A marked positive, persistent, wheal-and-flair response was recorded at the site of rocuronium injection, comparable to that of the positive control (histamine), with negative responses at the other sites. Three months later, she decided to undergo surgery again. In the operating room, the patient received an induction dose of propofol and cisatracurium instead of rocuronium. Thereafter, endotracheal intubation was performed, and the surgery was conducted successfully in the prone position. No adverse events occurred intraoperatively, and the patient was discharged without any complications.

\section{DISCUSSION}

This case report describes the usefulness of intraoperative sugammadex administration in treating an episode of confirmed rocuronium-induced anaphylaxis, which was temporally associated with a marked improvement in the

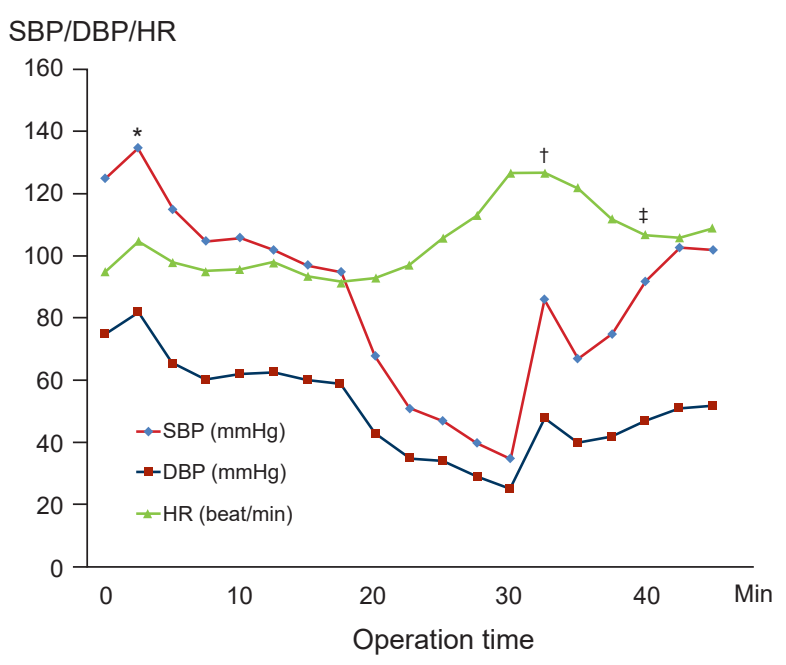

Fig. 1. Chart showing the vital sign changes. HR: heart rate, SBP: systolic arterial blood pressure, DBP: diastolic arterial blood pressure. ${ }^{*}$ Rocuronium injection and intubation. ${ }^{\dagger}$ Epinephrine. ${ }^{\ddagger}$ Sugammadex intravenous injection. 
patient's critical hemodynamic status. This case report provides evidence to support the role of sugammadex in the management of rocuronium-induced anaphylaxis.

The reported incidence of anaphylaxis induced during anesthesia has varied from 1:3,500 to $1: 20,000[8,9]$. Most cases have been reported in women and during the use of muscle relaxants. Neuromuscular blocking agents (NMBAs) account for most IgE-mediated anaphylactic reactions that occur during general anesthesia induction $[8,10]$. Among the muscle relaxants that induce anaphylaxis, rocuronium is the most common causative drug [11]. NMBAs induce the release of tryptase and histamine from mast cells, both of which have direct vasodilatory effects on the blood vessels and induce changes in capillary permeability, urticaria, erythema, angioedema, hypotension, and bronchospasm [12]. Independent risk factors associated with death were male sex, emergency setting, history of hypertension or other cardiovascular diseases, ongoing beta-blocker treatment, and obesity [13].

According to the World Allergy Organization (WAO), the diagnosis of anaphylaxis depends on the recognition of characteristic symptoms and signs that occur minutes to hours after exposure to a known or potential trigger [1]. Although the intradermal skin test or skin prick test are the gold- standard methods for identifying a potential anaphylactogen, they are indicators of the procedure and test concentrations used for most drugs. The optimal interval between the time of anaphylactic shock and the skin test is controversial. The test is commonly recommended in a minimum time interval of three weeks and no more than three months after the anaphylactic episode. In our case, intradermal skin test to identify the anaphylactogen was performed four weeks after the episode of anaphylactic shock.

When a patient is experiencing an anaphylactic shock, prompt acknowledgement as well as rapid and specific management is essential, including intravenous fluid replacement and the use of cardiovascular drugs. Epinephrine is the first-choice drug used to treat anaphylaxis [1]. Once an agent has been administered intravenously, it is difficult to eliminate it from the body. Sugammadex is a $\gamma$-cyclodextrin derivative with a truncated cone-like shape and a hydrophobic cavity. The molecular cavity of sugammadex encapsulates the steroid backbone of rocuronium with high affinity. Once enveloped within the sugammadex molecule, rocuronium cannot bind to acetylcholine receptors. This mechanism of sugammadex has a positive effect during the treat- ment of rocuronium-induced anaphylaxis [5].

Cases of sugammadex-induced anaphylaxis have been reported in countries that frequently use the drug. These cases of anaphylactic reactions appear to be more frequent at higher clinical doses [6]. Although sugammadex-induced anaphylaxis has been reported, sugammadex is a great antagonist of rocuronium. The optimal dose of sugammadex in such cases is unknown. Theoretically, it has been suggested that large doses (up to $16 \mathrm{mg} / \mathrm{kg}$ ) may be required to encapsulate all circulating rocuronium molecules in a patient's body [5]. This dose is dependent on the initial dose of rocuronium administered and the time elapsed since its administration. In our case, $200 \mathrm{mg}$ of sugammadex was administered because it was readily available. In the present case, this dose appeared to fully reverse the underlying neuromuscular block, as expected given that $80 \mathrm{~min}$ had elapsed since rocuronium administration $[14,15]$.

In conclusion, although cases of sugammadex-induced anaphylaxis have been reported, sugammadex is a useful rocuronium antagonist. It is noteworthy that sugammadex adequately reversed the adverse effects of rocuronium-induced anaphylaxis; however, the optimal dose to prevent anaphylaxis has not been reported yet. Therefore, further studies should be conducted to identify the optimal dose.

\section{CONFLICTS OF INTEREST}

No potential conflict of interest relevant to this article was reported.

\section{AUTHOR CONTRIBUTIONS}

Conceptualization: Seung-Ah Ryu. Data curation: SunMin Kim. Formal analysis: Sun-Min Kim, Sei-hoon Oh, Seung-Ah Ryu. Writing - original draft: Sun-Min Kim. Writing - review \& editing: Sei-hoon Oh, Seung-Ah Ryu. Investigation: Sun-Min Kim, Sei-hoon Oh. Supervision: Seung-Ah Ryu. Validation: Seung-Ah Ryu.

\section{ORCID}

Sun-Min Kim, https://orcid.org/0000-0002-1022-7781

Sei-hoon Oh, https://orcid.org/0000-0002-9476-5594

Seung-Ah Ryu, https://orcid.org/0000-0002-5544-3445 


\section{REFERENCES}

1. Simons FE, Ardusso LR, Bilò MB, El-Gamal YM, Ledford DK, Ring J, et al. World Allergy Organization. World Allergy Organization guidelines for the assessment and management of anaphylaxis. World Allergy Organ J 2011; 4: 13-37.

2. Harper NJ, Dixon T, Dugué P, Edgar DM, Fay A, Gooi HC, et al. Working Party of the Association of Anaesthetists of Great Britain and Ireland. Suspected anaphylactic reactions associated with anaesthesia. Anaesthesia 2009; 64: 199-211.

3. McDonnell NJ, Pavy TJ, Green LK, Platt PR. Sugammadex in the management of rocuronium-induced anaphylaxis. Br J Anaesth 2011; 106: 199-201.

4. Mertes PM, Laxenaire MC; GERAP. [Anaphylactic and anaphylactoid reactions occurring during anaesthesia in France. Seventh epidemiologic survey (January 2001-December 2002)]. Ann Fr Anesth Reanim 2004 23: 1133-43. French.

5. Jones PM, Turkstra TP. Mitigation of rocuronium-induced anaphylaxis by sugammadex: the great unknown. Anaesthesia 2010; 65: 89-90; author reply 90.

6. Peeters PA, van den Heuvel MW, van Heumen E, Passier PC, Smeets JM, van Iersel T, et al. Safety, tolerability and pharmacokinetics of sugammadex using single high doses (up to $96 \mathrm{mg} / \mathrm{kg}$ ) in healthy adult subjects: a randomized, double-blind, crossover, placebo-controlled, single-centre study. Clin Drug Investig 2010; 30: 867-74.

7. Kim KS. Clinical use of sugammadex. Anesth Pain Med 2011; 6:
307-13.

8. Fisher MM, Baldo BA. The incidence and clinical features of anaphylactic reactions during anesthesia in Australia. Ann Fr Anesth Reanim 1993; 12: 97-104.

9. Hepner DL, Castells MC. Anaphylaxis during the perioperative period. Anesth Analg 2003; 97: 1381-95.

10. Mertes PM, Laxenaire MC, Alla F; Groupe d'Etudes des Réactions Anaphylactoïdes Peranesthésiques. Anaphylactic and anaphylactoid reactions occurring during anesthesia in France in 1999-2000. Anesthesiology 2003; 99: 536-45.

11. Axon AD, Hunter JM. Editorial III: anaphylaxis and anaesthesia--all clear now? Br J Anaesth 2004; 93: 501-4.

12. Mertes PM, Moneret-Vautrin DA, Leynadier F, Laxenaire MC. Skin reactions to intradermal neuromuscular blocking agent injections: a randomized multicenter trial in healthy volunteers. Anesthesiology 2007; 107: 245-52.

13. Reitter M, Petitpain N, Latarche C, Cottin J, Massy N, Demoly P, et al. French Network of Regional Pharmacovigilance Centres. Fatal anaphylaxis with neuromuscular blocking agents: a risk factor and management analysis. Allergy 2014; 69: 954-9.

14. Gijsenbergh F, Ramael S, Houwing N, van Iersel T. First human exposure of Org 25969, a novel agent to reverse the action of rocuronium bromide. Anesthesiology 2005; 103: 695-703.

15. Jones RK, Caldwell JE, Brull SJ, Soto RG. Reversal of profound rocuronium-induced blockade with sugammadex: a randomized comparison with neostigmine. Anesthesiology 2008; 109: 816-24. 